\title{
Museus de ciência, divulgação científica e informação: reflexões acerca de ideologia e memória
}

\section{Daniel Maurício Viana de Souza}

\author{
Museólogo. Mestre em Ciência da Informação e \\ Professor do Departamento de História e \\ Antropologia do Instituto de Ciências Humanas da \\ Universidade Federal de Pelotas - UFPel
}

O crescente interesse na interelação entre ciência/ tecnologia e suas implicações no cotidiano dos diversos segmentos sociais ocasionam um aumento significativo de iniciativas destinadas a promover o acesso cada vez maior do público em geral aos produtos da ciência. Intenta-se analisar os aspectos ideológicos que permeiam as ações de divulgação científica operadas nos museus de ciência por meio das exposições, privilegiando a importância das práticas de operacionalização da informação de caráter científico e suas conseqüências na constituição da memória coletiva.

Palavras-chave: Museu de Ciência; Divulgação Científica; Informação; Ideologia; Memória; Patrimônio.

\section{Science Museum, scientific popularization, and information: reflections on ideology and memory}

The growing interest in the science/technology interrelation and its implications in daily life of various social segments lead to an increase in initiatives to promote access of the general public to science products. This paper intends to examine the ideological issues that characterize the actions of scientific popularization of science museums through exhibits. The importance of the practices of processing scientific information and its consequences for formation of social memory are emphasized.

Keywords: Science Museum; Scientific Divulgation; Information; Ideology; Memory; Heritage 


\section{Introdução}

Contemporaneamente, os museus de ciência vêm ocupando espaços cada vez mais significativos nos mais variados fóruns de debates científicos e acadêmicos. Os novos aparatos info-comunicacionais, aliados às mais diversas técnicas de implementação e apresentação de exposições, vêm sendo considerados temas potencialmente relevantes no âmbito social. O interesse crescente, embora tímido, se daria, fundamentalmente, devido à ênfase na divulgação científica, e às novas estratégias expositivas que possibilitariam, segundo muitos, uma maior participação do público nas atividades de popularização da ciência operadas no interior das exposições.

A divulgação científica, por vezes denominada "popularização da ciência" ou "vulgarização da ciência", constitui-se em um conjunto de procedimentos voltados à comunicação da ciência para o público em geral. As narrativas expositivas dos museus de ciência, via divulgação científica, pretendem ser capazes de promover diálogos e reflexões acerca das relações entre ciência e sociedade. Existiriam, entretanto, aspectos da divulgação científica nas instituições museológicas que apontariam para uma apresentação acrítica da ciência, onde faltariam maiores considerações acerca dos embates ideológicos presentes em suas construções e relações com o meio social (MARANDINO, 2001, p. 163).

A ideologia considerada por Thompson (1995) como um conjunto de significações que influenciam nas perspectivas simbólicas presentes na criação, legitimação e manutenção de relações desiguais de interesses, permite supormos a sua interrelação com a ciência, que estaria sempre "cercada do manto da ideologia do reino da razão, da verdade científica como verdade suprema, das promessas de um futuro radioso que faz a todos que queiram ajudá-la a crescer e a florescer" (SCHWARTZMAN, 1981 , p. 152-153).

Assim considerando, pretendemos refletir acerca dos aspectos ideológicos presentes nos processos de divulgação científica, operacionalizados por meio das exposições no interior dos museus de ciência. Objetivamos, ainda, tratar das relações fundamentais entre a informação de cunho científico presente no interior dos espaços expositivos museológicos e suas implicações nos quadros de construção da memória social.

\section{A relação museu e ciência moderna: aspectos da divulgação científica}

As origens dos museus de ciência encontram-se vinculadas ao fenômeno das coleções nos "gabinetes de curiosidades", espaços voltados às práticas científicas e humanistas, surgidos durante o embrionamento 
da ciência moderna ${ }^{1}$. Suas coleções de cunho científico passam a refletir, apoiadas basicamente no evolucionismo, a preocupação em demonstrar o desenvolvimento de uma sociedade "civilizada" e "ilustrada", tornando-se, assim, espaços de representação dos "avanços" sociais, políticos, ideológicos e científicos da nova ordem então estabelecida.

Em meados do século XIX, o Romantismo, sobretudo na qualidade de manifestação que se opunha ao racionalismo iluminista, e o Imperialismo europeu também influenciaram o desenvolvimento dos museus de ciência no alvorecer da modernidade. O conhecimento e o domínio de culturas outras determinaram o surgimento de diversas instituições museológicas espalhadas pelo mundo, contribuindo, ainda, para a construção de uma idéia de identidade nacional fortalecida, por conta de suas possibilidades de institucionalização da memória.

O desenvolvimento da ciência e tecnologia, desde o início do período moderno, desempenhou papel fundamental para a expansão quantitativa da produção industrial, o que demonstra o forte vínculo existente entre as noções de saber e poder. A essência de uma racionalidade herdeira do Iluminismo cultivou o solo para um cientificismo que se sustentaria na missão postulada da "organização científica" da humanidade. Este fenômeno teria para Chrétien (1994, p. 30) uma lógica dupla, pois ao mesmo tempo em que é um controle da natureza é também um controle do homem, uma vez que, desvendando-se as leis que regeriam o meio natural, seria possível ditar à sociedade modos e costumes de vida que fossem de acordo com essas leis. Estas perspectivas relacionariam o saber e a produção científica intrinsecamente à "produção de representações úteis ao domínio material do mundo e de um discurso simbólico legitimador" (FOUREZ, 1995, p. 103). Diversos autores, por outro lado, argumentam que a ciência, e sua produção de saberes, não ocupa lugar externo em relação à sociedade que a produz e que goza de seus resultados, sendo ela "uma entre outras atividades sociais, integrada ao funcionamento e ao equilíbrio da vida coletiva" (CHRÉTIEN, 1994, p. 78). O saber científico se encontraria, assim, permeado de valores e representações que se referem ao contexto sócio-histórico na qual se insere. Em última instância, "a sociedade determina as formas e conteúdos do saber científico".

Neste contexto do final do século XIX, os Museus de Ciência e Técnica desenvolveram-se como instituições voltadas ao trabalho de investigação científica e preocupadas com o domínio histórico do desenvolvimento científico e tecnológico, além de representarem toda uma perspectiva de um anunciado progresso, fruto das novas formas de cooperação entre ciência, técnica e indústria. As possibilidades de implicações da ciência e da tecnologia na esfera social marcam de maneira indelével o território das práticas museológicas científicas desde a

\footnotetext{
${ }^{1}$ A ciência moderna se constitui a partir da "Revolução Galileana" ocorrida no século XVII, em um contexto sócio-histórico de ascensão da burguesia como classe hegemônica ao poder, na qual se delinearam especificidades de uma racionalidade de cunho instrumental e novas perspectivas acerca da relação homem/natureza (JAPIASSU, 1982).
} 
primeira metade do século $X X$, provocando uma proliferação de museus de ciência em diversas partes do mundo ocidental.

Além dos museus de ciência tradicionais, surgem, a partir da segunda metade do século $X X$, novas concepções teóricas e práticas de difusão dos produtos da ciência e da tecnologia, que alcançam desenvolvimento sem precedentes na história, tanto em termos de quantidade quanto em diversidade qualitativa: são os denominados "centros de ciência" ou "science centrum". Estas novas vertentes institucionais, por dispensarem objetos, diferenciam-se, portanto, das instituições museológicas científicas ditas tradicionais. O "centro de ciências", na concepção de Bragança Gil (1988, p. 58), pode ser considerado fruto das novas perspectivas de inserção da ciência e da tecnologia no cotidiano do homem comum. Tais instituições caracterizamse por lançar mão de variados meios de comunicação e de exposição de caráter interativo, com vistas à motivação, aproximação e educação através da própria experiência.

Uma das maneiras de difundir os discursos da ciência, fazendo com que se consiga a abrangência e a assimilação necessárias para sua legitimação, é por meio da divulgação científica. Tal processo de veiculação da informação científica e tecnológica está ligado à esfera da comunicação científica que, por sua vez, é uma das mais relevantes áreas de interesse da Ciência da Informação. Cabe aqui fazer a distinção entre estes dois conceitos, uma vez que a comunicação científica tem como interlocutores os próprios pares cientistas e a divulgação científica é voltada à circulação da informação em ciência e tecnologia para o público em geral, e não somente para especialistas/cientistas.

É comum considerar-se que os primeiros esforços em direção às práticas de divulgação científica tenham sido empreendidos ao mesmo tempo em que a ciência moderna surgiu e foi se estabelecendo. Tal assertiva, entretanto, seria contradizer os seus próprios fundamentos, sabendo que naquela época o acesso aos conhecimentos produzidos pela ciência era privilégio exclusivo de uma elite (REIS, 2005, p.1). Seja como for, é preciso reconhecer que o caráter atual das propostas de divulgação científica começou a se delinear com o advento da tecnociência resultante da Revolução Industrial. Desde então, na medida em que a ciência e tecnologia vão se tornando cada vez mais estratégicas para as esferas política, econômica e cultural, vai crescendo também o interesse geral por assuntos referentes aos postulados avanços da ciência e suas possibilidades de melhorar a vida cotidiana dos diversos extratos sociais.

Apesar do discurso que postula a comunicação entre ciência e sociedade através da familiarização do público com a natureza do trabalho da ciência e a vida dos cientistas, Gonzalez (1992, p. 19) ressalta que, na prática, trata-se apenas de uma relativa democratização do conhecimento produzido pela ciência. Isto porque o que se divulgaria, na realidade, nada mais seria do que o produto final, pronto e acabado, encobrindo assim todo o processo de construção do saber científico que se encontraria permeado por conflitos, idiossincrasias e interesses ideológicos. Para que seja possível uma efetiva divulgação científica, deveria-se reconhecer que 
o produto ou o saber científico que se pretende divulgar, em seu processo de construção, reflete discursos dentro do próprio universo da ciência, e está implicado diretamente no contexto social.

Nos museus de ciência, as construções informacionais advindas de premissas do conhecimento científico encontram na exposição um meio peculiar para a divulgação científica, característica que se deve à ênfase e à instrumentalização que é dada ao objeto musealizado.

\section{Memória e informação: construindo significados ideológicos}

O conceito de memória vem sendo abordado fundamentalmente sob dois pontos de vista divergentes: um que trata da memória como algo subjetivo e individual e outro que considera a memória uma construção eminentemente coletiva. A vertente subjetivista, que encontra em Bergson seu maior representante, coloca-se pouco pertinente no que tange à percepção do fenômeno museológico, uma vez que os fatores psicológicos e individuais encontrar-se-iam, eles próprios, subjugados às determinantes sociocoletivas (BOSI, 1979).

Reconhecendo que o ser humano, na sua qualidade de sujeito social, convive em um determinado grupo, compartilhando acontecimentos e experiências, Halbwachs (1990, p. 26) considera possível que haja uma identificação capaz de provocar o que ele chama de "confusão de passados". Com efeito, a proximidade, no sentido da convivência e do compartilhamento de experiências, nos remete a construções mnemônicas enquanto membros do grupo.

Na percepção de Pollak (1992), a memória, seja ela individual ou coletiva, é um fenômeno construído, no qual não se processa a parte da negociação de sentidos em função da presença do "outro". Tal configuração insere o processo de construção da memória no âmbito de disputas e conflitos sociais, e torna-o, consequentemente, passível de atribuições de valores. O próprio caráter "herdado" da memória - em virtude do freqüente reconhecimento a acontecimentos que não são vividos diretamente, mas que acabam adquirindo grande importância no imaginário coletivo - justifica seu valor e a agregação de sentidos identitários, dando a coerência e a face de continuidade tão importantes para a sobrevivência de qualquer grupo e para suas formas de pensar e agir.

Forjar elementos comuns e reconhecíveis, com o intuito de criar elos associativos, é tarefa que, em certa medida, contradiz a própria natureza de toda e qualquer atividade de memória, que se constitui com perfil heterogêneo, plural e conflituoso. A escolha dos conteúdos simbólicos desta pretensa unidade estará vinculada aos critérios para seleção e preservação do patrimônio cultural (SIMÃO NETO, 1988, p. 261). Embora atuem como instrumentos para a criação de elos identitários e unificadores, itens de coleção qualificados sob o status de patrimônio são, na realidade, objetos de conflitos e disputas materiais e simbólicas, representantes das disparidades sociais. Mas, por serem considerados 
"parte orgânica do passado" e porque através deles estabelecemos uma relação de continuidade com este passado, eles desempenhariam, na realidade, função de perpetuação das relações já estabelecidas (GONÇALVES, 1998, p. 267).

No que tange à questão da informacional, sob uma análise em termos etimológicos, a palavra informação - que vem do latim informare - significa "dar forma", "colocar em forma", o que remete aos sentidos de criação, apresentação e representação. Capurro (1985) respalda-se em Tomás de Aquino para buscar as origens epistemológicas do conceito informação - informatio -, denotando os aspectos ontológico, epistemológico, pedagógico e lingüístico. Informação, nestes termos, apontaria para os aspectos de mediação entre mente e objetos, uma vez que estes são percebidos pelos nossos sentidos.

Considerando, assim, o seu sentido formal/ordenador, Zeman (1970, p. 156-157) ressalta o caráter qualitativo - e não só quantitativo e organizador da informação, sempre voltada à questão da forma e não da materialidade do objeto. Nesta perspectiva, o autor sublinha o "caráter monístico" da informação. Mônada, segundo Giordano Bruno (séc. XVI), e também Leibniz (séc. XVIII), significa os "elementos das coisas"; isto é, representaria a menor partícula a partir de onde se constituiria a complexidade das formas. As mônadas seriam, assim, "átomos da natureza". Esta noção monística pode apontar para uma problemática bastante pertinente na atualidade sobre as questões que envolvem o papel da informação no processo de construção do conhecimento. Lopes (1998, p. 2) alerta que "o fracionamento do todo em mônadas funciona sob o mesmo modelo que o fracionamento atual do conhecimento em informação (as mônadas do século XX)". Isso que poderia motivar a crítica de que a informação não é indivisível como as mônadas, não se trataria de átomos rigorosamente herméticos do conhecimento, que por si mesmo é vasto e irregular. O que vale para nossa proposta aqui, entretanto, buscando na idéia de mônada associada à informação, é ressaltar o seu aspecto organizador capaz de "dar forma", fugindo ao domínio estrito da materialidade do objeto.

Segundo esta mesma lógica de raciocínio, em que não deve ser compreendida sob um olhar a priori do aspecto físico, Buckley (1983, p. 603) considera a informação não como ente ou objeto, mas "inerentemente relacional entre dois ou mais conjuntos de eventos", sendo seu significado, assim, construído na arena de interações sociais. No que tange à questão do significado, é fundamental que estejamos sempre atentos às limitações de possibilidade de uma representação abarcar todo um universo de conotações e domínios semânticos de um determinado evento ou objeto.

$\mathrm{Na}$ percepção de Capurro (1985, p. 7), informação em sentido hermenêutico-existencial, enquanto dimensão do nosso estado de convivência no mundo com os outros, significa "compartilhar um mundo comum tematicamente e situacionalmente". Admitindo que o homem não reflete a heterogeneidade do objeto, mas apenas aspectos eleitos da realidade total, o compartilhamento proposto por Capurro diria respeito às 
convenções a partir de determinadas formulações redutoras, subjetivamente selecionadas em seus aspectos pretensamente "mais importantes", sob o signo da organicidade - pois caso contrário, ela seria caótica.

Mesmo diante de todo um quadro que evidencia o caráter múltiplo e controverso do conceito de informação, não podemos esquecer que, por outro lado, existem certas premissas epistemológicas comuns ao fenômeno informação, como, por exemplo, seu domínio por excelência: o campo das relações sociais. Os diversos autores que de alguma maneira vêm pensando a informação a partir do escopo teórico da Ciência da Informação, embora de pontos de vista por vezes bastante estanques e divergentes, ratificam tal complexidade e heterogeneidade deste fenômeno. Brookes e MacGarry (1984), por exemplo, possui visões que se assemelham no sentido de considerar a informação uma espécie de matéria prima ou pequena partícula da estrutura do conhecimento. Perspectivas estas que remetem, de certa forma, a Belkin (1980), que se refere à informação quanto ao que ela é capaz de transformar as estruturas cognitivas. Um recorte do domínio informacional bastante importante é o relativo ao conceito de "informação científica" na definição soviética, sobretudo com Mikhailov (1980), referindo-se a todo conhecimento não só científico.

Uma das opções de se olhar a informação, que talvez possa dar conta de sua vasta abrangência, seria a de admitir que não há modelos de construção da informação, mas sim "ações de informação" que passam pelos diversos discursos e negociações de significados na teia social (GONZÁLEZ DE GOMÉZ, 1990). E, da mesma maneira, haveria todo um sistema de informação ao qual caberia a atribuição dos "valores de informação", pautados nos critério de pertinência e relevância segundo as relações estabelecidas nos processos discursivos no quadro social. No entender da autora, deveria haver uma "pragmática social" de circulação de informação, pautada em princípios de eficácia das ações informacionais. Ocorre, no entanto, que os sistemas de informação, uma vez institucionalizados no domínio estratégico e instrumental no interior de uma lógica "moderna-social-industrial-capitalista", atendem de maneira diferenciada e particularizada a demandas de usuários.

O museu, enquanto espaço de produção de conteúdos informacionais representativos da memória social, deve atentar à questão do objeto/patrimônio cultural em seus múltiplos aspectos, à luz de um aprofundamento teórico que não se prenda apenas aos aspectos formais. Zeman (1970, p. 165) adverte que, embora a informação seja inerente e inseparável da matéria, seu significado não se esgota na suas características físicas, "o objeto é mais rico que seu reflexo"; ela é sempre uma representação de determinada realidade sob o máximo de condensação possível. Jamais se apreende, desta forma, a variedade de um objeto em sua totalidade, mas sempre se escolhe apenas alguns aspectos.

Tal noção de "reflexo" configura-se essencial no que tange aos aspectos da musealização e da exposição do objeto. Separado de sua 
realidade inicial e transferido para um acervo, o objeto, além de passar por uma re-contextualização no espaço/tempo, que implicaria na redução de seus aspectos relacionais e mesmo numa percepção parcial das suas próprias características físicas, sofreria ainda agregação de novos referenciais e significados, de maneira a torná-los próprios para cumprir, no espaço museal, a função representativa no contexto de determinada narrativa, como "autênticas testemunhas, documentos e evidências de fatos naturais e sociais" (STRÁNSKÝ, 1981, p. 70).

Autores com Maroevic (2000, p. 6), para quem o objeto musealizado é "elemento de informação básico do conhecimento humano", e outros como Mensch; Pow e Schouten (1990, p. 60), ressaltam a importância dos aspectos semânticos no processamento técnico do objeto musealizado, o que pode garantir que a informação no âmbito do museu assuma caráter realmente fundamental na construção e interpretação da realidade social. Buckland (1991, p. 352), argumentando sobre a construção da categoria "informação-como-coisa" - que aponta para um grupo de definições que, embora considerem a necessidade da representação física da informação para fins de compreensão e manipulação, da mesma forma reconhecem que essas representações tangíveis diriam respeito tanto à informação de natureza concreta/material como à intangível/simbólica -, destaca a pertinência de tal noção, refererindo-se ao museu e sua característica de tratar essencialmente com objetos. Para o autor, por mais que a intenção de uma exposição museológica seja a de informar o público, como parte do processo de construção do conhecimento, esta perspectiva se baliza na operacionalização da informação a partir da "fisicalidade" do objeto.

Fica delineado, desta maneira, um prisma relacional da informação em que as possibilidades de inteligibilidade e significação não se esgotam nos aspectos físicos, sendo preciso um aprofundamento do olhar sobre o objeto para além de seu "reflexo". Toda formação discursiva operada a partir do espaço expositivo museológico se encontraria essencialmente alicerçada na informação/objeto museológico, uma "(...) representação do mundo sensível, através de bens concretos e simbólicos, produzidos e/ou coletados pelos agentes sociais" (LOUREIRO, 1996 p. 45). Assim, como o que se pode perceber na leitura extrínseca de um objeto - redutor e condensador de uma gama inestimável de significados possíveis -, toda representação, por si só, já significaria uma redução e uma parcialidade subjetiva na percepção. Desta maneira, as representações instrumentalizadas a partir da informação/objeto museológico corresponderiam a construções simbólicas intencionais, dando origem a práticas de significação parcialmente direcionadas.

Tais premissas implementadas na exposição museológica de ciência e, conseqüentemente, nas construções da memória científica, implicariam diretamente a percepção imprecisa da complexidade que recobre os aspectos referentes à memória coletiva. Na qualidade de instituição de memória, em sua face de representante de um domínio especializado do saber, competente no âmbito do tratamento dos ditos "bens culturais", sejam de origem histórica, artística, científica, dentre outros, o museu seria um "(...) espaço destinado à transmissão subliminar de conteúdos, 
tão subliminar que às vezes nem os próprios trabalhadores dos museus nos damos conta do quanto estamos vendendo de nossa ideologia ao público (...)" (LUMBRERAS SALCEDO, 1998. p. 37).

Mas a que estaríamos nos referindo, mais especificamente, quando admitimos que na órbita museológica se trabalha de maneira a reproduzir e transferir expressões de ordem ideológica? A categoria ideologia se encontra muito longe de possuir significado único e coerente. Sua profunda polissemia lhe dá ares conceituais múltiplos e muitas vezes contraditórios, fazendo com que sua apropriação seja também tão diversificada, assumindo contornos e funções difusas e dispersas, sempre de acordo com as demandas específicas de cada contexto em que o conceito é empregado.

Usada pela primeira vez em finais do século XVIII por De Tracy, a palavra ideologia significava uma espécie de "ciência da gênese das idéias", de acordo com o contexto racional/iluminista, capaz de investigar as leis que regem as possibilidades de surgimento e desenvolvimento das idéias. Desde o rompimento de Napoleão com os ideólogos franceses que antes lhe prestavam o serviço intelectual da construção de pressupostos teóricos propícios à legitimação racional do poder -, o termo ideologia passou a receber uma carga conceitual pejorativa e um sem número de definições ao longo da história.

Konder (2002, p. 10) sugere que, frente à abrangência conceitual que pode ser atribuída à ideologia, podemos, grosso modo, agrupar estas várias definições em dois metagrupos distintos. O primeiro denotaria um "significado fraco", designando "sistemas de crença políticas, conjuntos de idéias e valores cuja função é orientar comportamentos coletivos relacionados à ordem pública". O segundo, relativo ao "significado forte" da expressão ideologia, faz referência a "uma distorção no conhecimento".

Sob o prisma da tradição marxista, o conceito de ideologia estaria vinculado às condições materiais de produção da sociedade capitalista, com o pressuposto de que toda relação social subjuga a própria consciência, pois ela seria elaborada "a partir das relações sociais de produção", expressando assim a realidade "de modo simples, imediato e sem reflexão, que ocorreria somente a partir das condições reais de existência" (MÉSZÁROS, 2004, p. 65). Deste ponto de vista, a consciência individual se torna secundária frente a uma espécie de "consciência social"; que é a expressão própria da ideologia na prática de construção e validação de critérios que suprimem a realidade conflituosa da sociedade de classes, perpetuando a ordem já estabelecida alicerçada por mecanismos culturais, políticos, econômicos variados, além ainda de teorias e práticas científicas, assim como, segundo Mészáros (2004, p. 166), as "diversas filosofias e auto-reflexões da ciência referentes à sua função reguladora no complexo total das atividades humanas".

Existem, por outro lado, tendências teóricas e filosóficas inclinadas a não tratar a ideologia como um insumo exclusivamente pronto a atender os interesses dos grupos sociais dominantes. Magalhães (2005, p. 4) argumenta que "(...) ao entendermos que as idéias dominantes são as únicas possíveis, a homogeneidade proposta por elas torna-se realidade 
(...)" e, ao contrário do que postula o materialismo histórico, as idéias moldariam o real. Ainda nesta linha de pensamento, Eagleton (1997, p. 19-20) rejeita a idéia de que toda ideologia seja opressora e legitimadora, acentuando que, embora a ideologia seja recoberta por impulsos identificadores e homogeneizadores, ela é, de acordo com autor, "marcada e desarticulada por seu caráter 'relacional', pelos interesses conflitantes entre os quais deve manobrar incessantemente". Outros autores, como os que trabalham com a idéia de "pós-modernidade", propõem um esvaziamento do sentido radical do pensamento ideológico.

Embora reconheçamos os limites da penetração de formulações ideológicas como propulsoras de valores de identidade a partir de elementos homogeneizadores, admitimos, assim como Thompson (1995, p. 79), que a ideologia, em certo nível, consiste em formular subsídios simbólicos úteis para criar e manter relações de interesses e dominação.

O referido autor propõe uma perspectiva de análise do fenômeno ideológico que combata o que ele considera a "neutralização da ideologia". Ao considerar que todo fenômeno ideológico é também, e essencialmente, um fenômeno simbólico, o prisma thompsoniano é desenvolvido sem a preocupação com suas possíveis manifestações errôneas ou ilusórias.

No contexto dessa proposta, Thompson (1995) identifica aspectos essenciais, tais como a questão do sentido - referindo-se ao sentido das formas simbólicas, parte integrante do meio social correspondente a uma série de atitudes e ações, lingüísticas ou não, que de alguma forma são responsáveis pela construção de significados no âmbito social; a questão da dominação - diretamente relacionada à perspectiva de poder, nesse caso especificamente o poder assimétrico; e, finalmente, a maneira como pode o sentido ou o significado agir para estabelecer e sustentar relações desiguais de interesses.

Neste caso existem, no prisma de Thompson (1995), cinco vias por meio das quais a ideologia pode atuar. São elas: legitimação - relações específicas podem ser sustentadas desde que pareçam inegavelmente legítimas diante de um determinado contexto; dissimulação - ocultar, negar, ou mesmo desviar a atenção, são estratégias para que não se discutam as relações de interesse já estabelecidas; unificação - a partir da criação, em nível simbólico, de elementos de identificação coletiva, à parte de qualquer diferença e incompatibilidade que possa existir, é um meio de preservar as relações existentes; fragmentação - ao contrário da forma anterior, relações dominantes podem continuar estabelecidas criando formas simbólicas de segmentação e afastamento do "outro", do "diferente", daquele que "não pertence"; reificação - criar a sensação de naturalidade, e conseqüentemente de eternização de uma determinada situação histórica-transitória-específica, é também um meio para se manter as relações vigentes.

No contexto de tal abordagem, são fundamentais para nossa proposta dois destes cinco aspectos apontados por Thompson (1995), para que se estabeleçam e se sustentem - balizados por elementos simbólico-ideológicos - relações desiguais de interesses: o de "unificação", 
por possuir características pretensamente identificadoras no interior de grupos coletivos heterogêneos, que são aspectos que definem o conceito de "patrimônio" - fundamental no que se refere à construção da memória no âmbito coletivo; e o de "reificação", que o autor vai recuperar de Lukács (1987) e retrabalhá-lo de tal forma que cria a possibilidade de traçar paralelos com as questões referentes à ciência e suas formas simbólicas de sobrevalorização, inspiradas em um cientificismo que mascara a transitoriedade e os laços sócio-históricos que caracterizam a produção e o saber científico.

\section{Considerações gerais}

Na qualidade de instâncias de representação da memória coletiva, os museus de ciência vêm atuando como espaços de preservação, gestão e divulgação da ciência, por meio de suas exposições; constituindo loci para a construção de significados que, de certo modo, contribuem para delinear os contornos da memória científica. A partir desta perspectiva, existem questões fundamentais que apontam para uma ligação estreita entre os aspectos ideológicos de estabelecimento e legitimação de relações desiguais de interesses, e a informação construída e resignificada através dos objetos musealizados, na qualidade de representantes legítimos do patrimônio científico. Esta relação implicaria atividades de divulgação dos insumos informacionais/científicos museológicos em seus processos de construção de uma memória da ciência à margem de determinados conflitos e diferenças inerentes às heterogêneas configurações sócio-políticas e culturais em que se dão as práticas científicas.

Os sinais da "euforia cientificista" continuam ainda na atualidade sendo (re)construídos e propagados na sociedade em geral, como forma de legitimar os mais diversos ramos da atividade científica em suas postuladas "missões", em prol do desenvolvimento e da melhoria da vida humana. Tal realidade impossibilita uma perspectiva da ciência enquanto mais uma dentre as demais atividades humanas e não como prática que assume ares de excepcionalidade, seja por objetividade ou por neutralidade. A divulgação científica implementada sem a preocupação com as diversas etapas do processo de construção da ciência, além de encobrir seus aspectos de provisoriedade, contribui para uma configuração ideológica, pautada apenas nos seus resultados. O acesso à ciência e à tecnologia fica mais especificamente restrito aos resultados que podem, de alguma maneira, implicar em uma instrumentalização ou em uma aplicação comprometida em "civilizar", de acordo com os parâmetros de "avanço" e "evolução".

A informação assim produzida nos museus de ciência corresponderia a reduções "reflexivas" das relações sociais, recortando e estabelecendo significados que possam cumprir o papel ideológico de fundação e/ou manutenção de relações específicas de poder e/ou interesses. A divulgação científica operada nos museus de ciência pode se aproximar do cumprimento de seus objetivos pretendidos de contribuição ao acréscimo 
da qualidade de vida por meio do acesso e da compreensão ampla da ciência e da tecnologia, somente criando meios para que se perceba a inserção intrínseca dos processos de construção dos produtos e saberes científicos na trama sócio-histórica. É necessário também deixar claro que os discursos científicos refletem interesses do próprio universo da ciência, implicando diretamente no contexto social.

\section{Referências}

BELKIN, N. J. Anomalous states of knowledge as a basis for information retrieval. The Canadian Journal of Information Science, v.5, p.133-143, 1980.

BOSI, E. Memória e sociedade: lembrança de velhos. São Paulo: T.A. Queiroz, 1979.

BRAGANÇA GIL, F. Museus de ciência: preparação do futuro, memória do passado. Colóquio Ciências. Revista da Cultura Científica, n 3, out./1988.

BROOKES, B. C. Lenin: the founder of informatics. Journal of Information Science, v.8, p. 221-231, 1984.

BUCKLAND, M. K. Information as thing. Journal of American Society for Information Science, v. 42, n. 5, p. 352-360, 1991.

BUCKLEY, W. Signals, meaning, and control in social systems. In: MACHLUP, F.; MAUSTIELD, U. (Orgs.) The study of information interdisciplinary menages. USA: John Wile \& Jons Inc., 1983.

CAPURRO, R. Epistemology and information science. In: REPORT TRITALIB-6023, ago. 1985. Disponível em: < stuttgart.de/ capurro/trilha.htm>. Acesso em: 26 maio 2009.

CHRÉTIEN, C. A Ciência em ação: mitos e limites. Campinas: Papirus, 1994.

EAGLETON, T. Ideologia: uma Introdução. São Paulo: UNESP/Boitempo, 1997.

FOUREZ, G. A construção das ciências: introdução à filosofia e à ética das ciências. São Paulo: UNESP, 1995.

GONÇALVES, J. R. Autenticidade, memória e ideologias nacionais: o problema dos patrimônios culturais. Revista Estudos Históricos, Rio de Janeiro, v. 1, n. 2, p. 264 - 275, 1988.

GONZALEZ, M. I. A divulgação científica: uma visão de seu público leitor. 143 f. Dissertação (Mestrado em Ciência da Informação) - IBICT/CNPqECO/UFRJ, Rio de Janeiro, 1992.

GONZÁLEZ DE GÓMEZ, M. N. O objeto de estudo da Ciência da Informação: paradoxos e desafios. Ciência da Informação, Brasília, v.19, n.2, p. 117-122, jul./dez. 1990.

HALBWACHS, M. A memória coletiva. São Paulo: Vértice, 1990. 
JAPIASSU, H. Nascimento e morte das ciências humanas. Rio de Janeiro: Francisco Alves, 1982.

KONDER, L. A questão da ideologia. São Paulo: Companhia das Letras, 2002.

LOPES, L. C. A informação: a mônada do século XX. Ciberlegenda, Niterói, n.1, 1998. Disponível em: < http://www.uff.br/mestcii/lclop2.htm>. Acesso em: 26 maio 2009.

LOUREIRO, J. M. M. Labirinto de paradoxos: informação, museu e alienação. 1996. Dissertação (Mestrado em Ciência da Informação) CNPq/IBICT-UFRJ/ECO, Rio de Janeiro, 1996.

LUKÁCS, G. Ontologia do ser social: Marx. São Paulo: Ciências Humanas , 1987.

LUMBRERAS SALCEDO, L. G. Museu Nacional. In: SEMINÁRIO SOBRE MUSEUS NACIONAIS, n.?, 20-24 jun., 1988. Perfil e perspectivas. Rio de Janeiro, SPHAN/Pró-Memória, 1988. Mimeo.

MAGALHÃES, L. H. O Conceito de Ideologia. Disponível em: <http://www.fanorpi.com.br/web/atividades/artigos/Ideologia.doc>.

Acesso em: 08 jan. 2005.

MARANDINO, M. A pesquisa e a produção de saberes nos museus de ciência. História, Ciências, Saúde: Manguinhos, v. 1, n. 1, p. 163, jul./ago. 1994.

MAROEVIC, Ivo. Museology as a field of knowledge. In: MUSEOLOGY. Paris: International Council of Museums - ICOM, 2000. p. 5-7. (COM. ICOM STUDY SERIES, v. 8.).

MÉSZÁROS, I. O poder da ideologia. São Paulo: Boitempo, 2004.

MENSCH, Peter V.; POUW, Piet J. M.; SCHOUTEN, Frans F. J. Metodologia da museologia e treinamento profissional. Cadernos Museológicos, Rio de Janeiro, v.3, p. 57-56, out. 1990.

MIKHAILOV, A. I. Estrutura e principais propriedades da informação científica. In: GOMES, H. E. (Org). Ciência da Informação ou Informática? Rio de Janeiro: Calunga, 1980. p. 70-89.

POLLAK, M. Memória e identidade social. Estudos Históricos, Rio de Janeiro, v. 5, n. 10, p. 201 - 215, 1992.

REIS, J. O que é divulgação científica? São Paulo: Núcleo José Reis de Divulgação Científica; Seção Divulgação Científica. Disponível em: <http://www.eca.usp.br/nucleos/njr/>. Acesso em: 4 set. 2005.

SCHWARTZMAN, S. Ciência, universidade e ideologia: a política do conhecimento. Rio de Janeiro: Zahar Editores, 1981.

SIMÃO NETO, A. Nova história, novo museu? História Questões e Debates, Curitiba, v. 5, n. 9, p. 1-2, 1985. 
STRÁNSKÝ, Z. Z. The theory of systems and museology. Museological Working Papers 1, p. 70-73, 1981.

THOMPSON, J. B. Ideologia e cultura moderna: teoria crítica na era dos meios de comunicação de massa. São Paulo: Vozes, 1995.

ZEMAN, J. Significado filosófico da noção de informação. In: ZEMAN, J. $O$ conceito de informação na ciência contemporânea. Rio de Janeiro: Paz e Terra, 1970. 